\title{
Cointegration Tests Under Multiple Regime Shifts: An Application to the Stock Price-Dividend Relationship
}

\author{
VASCO J. GABRIEL \\ Department of Economics, University of Surrey, UK and NIPE-UM, Portugal \\ Luis F. Martins* \\ Department of Quantitative Methods and UNIDE, ISCTE-LUI, Portugal
}

June $2010^{\dagger}$

\begin{abstract}
We examine the properties of several residual-based cointegration tests when long run parameters are subject to multiple shifts driven by an unobservable Markov process. Unlike earlier work, which considered one-off deterministic breaks, our approach has the advantage of allowing for an unspecified number of stochastic breaks. We illustrate this issue by exploring the possibility of Markov switching cointegration in the stock-price dividend relationship and showing that this case is empirically relevant. Our subsequent Monte Carlo analysis reveals that standard cointegration tests are generally reliable, their performance often being robust for a number of plausible regime shift parameterizations.

Key Words: Present value model; Cointegration tests; Markov switching.

JEL Classification: C32; G12; E44
\end{abstract}

\footnotetext{
${ }^{*}$ Corresponding author. Address: UNIDE and Department of Quantitative Methods, ISCTE-LUI, Business School, Av. das Forças Armadas, 1649-026 Lisbon, Portugal. E-mail: luis.martins@iscte.pt. Tel: + 35121 7903439. Fax: + 351217903941.

${ }^{\dagger}$ Financial support under grant PTDC/ECO/68367/2006 from the Fundação para a Ciência e Tecnologia is gratefully acknowledged. We thank Stephen Hall, Zacharias Psaradakis, Yongcheol Shin, Ron Smith, and Martin Sola for helpful comments and suggestions.
} 


\section{Introduction}

The concept of cointegration has dominated the debate in time series econometrics in the past decade, by stressing the possible existence of long run equilibrium relationships among nonstationary variables. However, researchers have been concerned with the effects that structural changes may have on inference in models with cointegrated variables. Indeed, failure to detect and account for parameter shifts is known to be a serious form of misspecification which adversely affects inference procedures and generally leads to poor forecasting performance. Such issues are especially relevant for cointegration analysis, since it normally involves long spans of data, which are likely to exhibit structural breaks.

Since the seminal work of Perron (1989), it is known that unit root tests have difficulties (i.e. low power) in distinguishing between an $I(1)$ processes and $I(0)$ processes with breaks. Conversely, Leybourne et al. (1998) and Leybourne and Newbold (2000) demonstrated that routine application of Dickey-Fuller tests when the true process is $I(1)$ with a relatively early break leads to frequent rejections of the null of a unit root.

The implications of structural breaks for the performance of stationarity tests were studied by Lee et al. (1997). They showed that when an existing break is ignored, these tests will be biased towards rejecting the null of stationarity in favour of the false alternative of a unit root. Notwithstanding this, there will be no power losses if the unit root alternative is true, since the limiting distribution is asymptotically invariant to this type of shifts.

Concerning the effects of changes in variance, Hamori and Tokihisa (1997) showed that spurious stationarity will also arise if Dickey-Fuller tests are applied to a process that suffers an upward break in variance. Early shifts will contribute to increase the size distortions and the effects do not seem to disappear asymptotically. On the other hand, Kim et al. (2002) considered the case of a decrease in variance and demonstrated that, unlike what was conjectured by Hamori and Tokihisa (1997), severe spurious rejections occur in this situation.

While the literature on the impact of structural breaks on unit root tests is large, papers specifically dealing with the effect of parameter non-constancy on cointegration tests are less abundant. Gregory et al. (1996) found that, in the context of the linear quadratic model, the Dickey-Fuller test suffers considerable power losses in the presence of a structural break. This is not necessarily a weakness, though, since the alternative of Engle-Granger cointegration involves a time-invariant relationship. These conclusions are further supported by the evidence presented in Gregory and Hansen (1996). Campos et al. (1996) examined the properties of cointegration tests when the marginal process of one of the cointegrating regressors is $I(0)$ with a break, confirming the decrease in power of the Dickey-Fuller test. It should be noted, however, that these studies are limited in scope, in the sense that they only consider one type of structural break (single deterministic shift) and concentrate on the Dickey-Fuller cointegration test.

In turn, given the flexibility of Markov switching models, it would be natural to extend their use to model changes in long-run relationships. Hall et al. (1997) and Krolzig (1997), for example, illustrate the usefulness of such a specification by analyzing the Japanese consumption function and co-movements in international business cycles, respectively. Nevertheless, these papers do not explicitly analyze the effects of Markov-type changes on the properties 
of cointegration tests. The effects of Markov shifts on unit root tests were recently investigated by Nelson et al. (2001) and Psaradakis (2001, 2002), who demonstrated that both standard unit root tests and tests that are robust with respect to a single break face serious difficulties in the presence of Markov regime switching. The present paper may be viewed as an extension of this work to the case of cointegration tests.

As a simple illustration of the effects of Markov regime shifts in a cointegrating relationship, consider the simple case of a bivariate relationship where only the intercept is switching, so that

$$
y_{t}=\alpha_{0}+\alpha_{1} S_{t}+\beta x_{t}+u_{t}
$$

with $y_{t}$ and $x_{t}$ both $I(1)$ variables, $S_{t}$ is a two-state, homogeneous first-order Markov chain with transition probabilities $p_{i j}=\operatorname{Pr}\left(S_{t+1}=j \mid S_{t}=i\right)$. If switching is not accounted for, then the researcher would be estimating $y_{t}=\mu+\beta x_{t}+e_{t}$, where $e_{t}=\alpha_{1} S_{t}+u_{t}$. Hence, we see that not accounting for regime switching will introduce further autocorrelation in the errors of the cointegrating regression. Following Nelson et al. (2001) and Psaradakis (2002), it is straightforward to show that, for $\sum_{i} p_{i i} \neq 1$, the strength of autocorrelation in $\left\{e_{t}\right\}$ will increase with the magnitude of the breaks, as well as with the persistence in the Markov chain that drives the regime shifts.

Note, however, that no procedures have been developed to test cointegration in such a setting. Thus, in this paper, we investigate the ability of residual-based cointegration tests when the long-run parameters are subject to multiple shifts driven by an unobservable Markov process. We focus on residual-based procedures, as these are the most commonly used tests in empirical applications. We consider the popular Augmented Dickey-Fuller (ADF) residual-based test, as well as tests proposed by Phillips and Ouliaris (1990) and Gregory and Hansen (1996). The latter are designed to be robust with respect to regime shifts in the cointegration vector. In addition, we analyze the test for the null hypothesis of cointegration proposed by McCabe et al. (1997). Finally, we investigate whether or not the time-varying cointegration approach of Park and Hahn (1999) is able to detect Markov switching-type cointegration. While this is a more general formulation that detects smoothly changing cointegrating coefficients, it could be able to detect our specification, which only considers two possible states.

We assume that distinct cointegration regimes may exist, which are randomly selected by nature according to the realization of an unobservable Markov process. Unlike previous work, which either considered an one-off deterministic break or assumed that the break points are known when cointegration is being tested, our specification has the considerable advantage of allowing for an unspecified number of endogenous stochastic changes in regime. We also analyze the implications of changing error variances, an issue that was not considered in earlier work on the subject.

To illustrate the problem, we consider the long run relationship between stock prices and dividends. We discuss how Markov-type shifts in the cointegration vector can arise in this case. Indeed, this framework is consistent with several explanations for the observed asymmetries in, and departures from, the long run price-dividend relationship, thus motivating the usefulness of this study. Also, we use this example to provide empirically plausible parameterizations (in particular, the magnitude of parameter shifts) of the general case in (1) 
discussed above. Naturally, we recognize that none of the tests analyzed in this paper were specifically designed for that particular purpose. Nevertheless, given that no direct testing procedures are available for Markov switching cointegration, we believe that, by characterizing the properties of existing tests in this context, we can shed some light on the findings of previous literature and establish some guidance for future empirical practice.

The remainder of the paper is organized as follows. Section 2 briefly reviews the cointegration tests of interest. In Section 3 we consider the possibility of a Markov switching long run relationship between stock prices and dividends and show that this case is empirically relevant, with an application using US, UK and Swedish data. Section 4 describes the experimental design and reports and discusses the results of the experiments. A final section concludes.

\section{Cointegration Tests}

In this section, we provide a brief description of the cointegration tests examined in the empirical section and subsequent Monte Carlo study. Given the model

$$
y_{t}=\delta^{\prime} c_{t}+\beta^{\prime} x_{t}+u_{t},
$$

where $z_{t}=\left(y_{t}, x_{t}^{\prime}\right)^{\prime}$ is a $(1+k)$-vector of $I(1)$ variables and $c_{t}$ is a vector of deterministic terms (such as a constant or time trends), the variables in $z_{t}$ will be cointegrated if $\left\{u_{t}\right\}$ is stationary. To test this hypothesis, we employ "standard" tests with the null hypothesis of no cointegration, tests which have cointegration as their null, as well as cointegration tests that allow for regime shifts.

\subsection{Standard Cointegration Tests}

The ADF and the $Z_{\alpha}$ tests of Phillips and Ouliaris (1990) test whether the residuals $\hat{u}_{t}$ from (2) have an autoregressive unit root. While the ADF test corrects for serial correlation by adding lagged $\Delta \hat{u}_{t}$ terms in the test regression $\Delta \hat{u}_{t}=\rho \hat{u}_{t-1}+\eta_{t}$, the Phillips-Ouliaris test make use of a nonparametric modification, which involves the estimation of the long-run variance of the errors $\left\{\eta_{t}\right\}$. To choose an appropriate lag length for the ADF test, we adopt a downward testing selection procedure based on two-sided 5\%-level $t$-type tests for the significance of the coefficient on the longest lag, with the maximum lag length set equal to 6 . For the $Z_{\alpha}$ test, the long-run variance of $\left\{\eta_{t}\right\}$ is estimated by using a prewhitened quadratic spectral kernel estimator with a data-based bandwidth and a first-order autoregressive prewhitening filter, as recommended in Andrews and Monahan (1992).

\subsection{Gregory-Hansen Tests}

We also consider the tests proposed by Gregory and Hansen (1996), which consider an alternative hypothesis in which the cointegrating vector may be subject to a regime shift at an unknown time. They analyzed models that accommodate, under the alternative hypothesis of cointegration, the possibility of changes in parameters. The testing procedures involve computing the usual statistics ( $G H-A E G$ and $G H-Z_{\alpha}$ ) for all possible break points $\tau \in J$ and 
then selecting the smallest value obtained, since it will potentially present greater evidence against the null hypothesis of no cointegration ${ }^{1}$.

These test statistics have non-standard limiting distributions with no closed form and, therefore, critical values were obtained by resorting to simulation methods. In this paper, we examine a type of structural break that was not previously considered, namely a change in slope and no constant term (consistent with the theoretical present value model of stock prices and dividends discussed below),

$$
y_{t}=\beta_{1}^{\prime} x_{t}+\beta_{2}^{\prime} x_{t} D U_{t}+u_{t},
$$

where $D U_{t}$ is a dummy variable such that $D U_{t}=0$, if $t>[T \tau]$ and $D U_{t}=1$, if $t \leq[T \tau]$, with [.] denoting the integer part operator.

For comparison, and following Gregory and Hansen (1996, p. 110), we obtained critical values for this model, with a single regressor, using the same response surface: with 10,000 replications for sample dimensions $T \in\{50,100,150,200,250,300\}$, critical values at the $p$ percent level are obtained and then the regression

$$
C(p, T)=\psi_{0}+\psi_{1} T^{-1}+\text { error }
$$

is run. The critical values at the $5 \%$ significance level for model (3) are -4.192 for the $G H-A D F$ test and -30.322 for the $G H-Z_{\alpha}$ test, respectively.

\subsection{Tests with Cointegration as the Null Hypothesis}

The tests described above are based on the principle of testing for a unit root in the residuals of the cointegrating regression. Other tests have been developed which test whether the residuals are stationary and, therefore, have cointegration as the null hypothesis. Since we are focusing on the effects of neglected parameter changes, it is also interesting to relate cointegration tests with structural change tests, as the former may be derived from the latter.

Hansen (1992) proposed some LM-type structural change tests in cointegrated models, making use of the fully-modified OLS (FM-OLS) estimator. A versatile feature of those tests is the possibility of using them as cointegration tests. In fact, if the alternative hypothesis is that the intercept follows a random walk, then structural change testing becomes cointegration testing, albeit with the null hypothesis of cointegration. In model (2), if $y_{t}$ and $x_{t}$ are not cointegrated, then the error term $u_{t}$ is $I(1)$. Decomposing $u_{t}$ so that $u_{t}=w_{t}+v_{t}$, with $\left\{w_{t}\right\}$ being a random walk and $\left\{v_{t}\right\}$ an $I(0)$ process, model (2) then becomes

$$
y_{t}=\alpha_{t}+\beta^{\prime} x_{t}+v_{t}
$$

with $\delta^{\prime} c_{t}=\alpha_{t}=\alpha+w_{t}$, that is, the intercept "absorbs" the random walk $w_{t}$ when there is no cointegration. In view of this fact, Hansen (1992) suggested using the statistic

$$
L_{c}=\frac{\sum_{t=1}^{T} \hat{s}_{t}^{\prime} \hat{M}_{t}^{-1} \hat{s}_{t}}{T \hat{\omega}_{1.2}}
$$

to test the null of cointegration, where $\hat{s}_{t}$ represents the scores associated with the FM-OLS estimates, the weighting matrix $\hat{M}$ is the moments matrix of the regressors and $\hat{\omega}_{1.2}$ is a

\footnotetext{
${ }^{1} \tau$ denotes the unknown relative timing of the break point and the trimming region is $J=(0.15,0.85)$, following Gregory and Hansen (1996).
} 
consistent estimate of the (conditional) long-run variance of $\left\{u_{t}\right\}$. However, this statistic was designed to test the stability of the whole cointegration vector, so there are advantages in regarding a version that tests only (partial) structural change in the intercept. This is related to the well known statistic of Kwiatkowski et al. (1992) (KPSS henceforth) to test for stationarity.

Shin (1994), Harris and Inder (1994) and McCabe et al. (1997), for example, extend its use to test for the null hypothesis of cointegration. Here, we use the latter version

$$
M L S=\frac{\sum_{t=1}^{T}\left(\sum_{j=1}^{t} \hat{\varepsilon}_{j}\right)^{2}}{T^{2} \hat{\sigma}^{2}},
$$

based on the dynamic OLS (DOLS) estimator of Saikkonen (1991) with filtered residuals $\left(\hat{\varepsilon}_{j}\right)$ from an $\operatorname{ARIMA}(p, 1,1)$ model and the variance estimator $\left(\hat{\sigma}^{2}\right)$ proposed in Leybourne and McCabe (1999); see McCabe et al. (1997) for more details on the computation of the statistic.

\subsection{Time-varying cointegration}

As explained in the Introduction, we are interested in a cointegration setup in which the relationship is allowed to change over time. Tests devised for nonlinear cointegration, such as Breitung (2001) or Saikkonen and Choi (2004), for example, could be useful in this context. Instead, we follow the suggestion of Granger (2008) that any non-linear model can be approximated by a time-varying parameter linear model. This principle was implicitly introduced by Park and Hahn (1999) in cointegrated relationships (and developed further in Bierens and Martins, 2010).

Park and Hahn (1999) propose a time-varying approach in which the cointegration vector is modeled as a smooth function and semi-parametrically parameterized by a Fourier expansion. They suggest two tests for the null hypothesis of standard cointegration against the alternative of time-varying cointegration, with statistics given by

$$
\widehat{\tau}_{1}=\frac{\sum_{t=1}^{T} \widehat{u}_{t}^{2}-\sum_{t=1}^{T} \widehat{\epsilon}_{t}^{2}}{\widehat{\omega}_{T \kappa}^{2}}, \widehat{\tau}_{2}=\frac{\sum_{t=1}^{T}\left(\sum_{i=1}^{t} \widehat{u}_{i}\right)^{2}}{T^{2} \widehat{\omega}_{T \kappa}^{2}},
$$

where the $\widehat{\epsilon}_{t}$ 's are the residuals of the regression of $y_{t}$ on $x_{t}$ and $t, t^{2}, \ldots, t^{n}$, and

$$
\widehat{\omega}_{T \kappa}^{2}=\frac{1}{T} \sum_{|k|<\ell_{T}} g\left(k / \ell_{T}\right) \sum_{t=k+1}^{T} \widehat{u}_{\kappa, t} \widehat{u}_{\kappa, t-k}
$$

is a long-run variance estimator, $g(\cdot)$ is a kernel function with truncation lag $\ell_{T}$ and the $\widehat{u}_{\kappa, t}$ 's are the residuals of the regression of $y_{t}$ on $\varphi_{i}(t / T) x_{t}$ for $i=1, \ldots, K$, with the $\varphi_{i}$ 's Fourier and other functions. As to the latter, we consider

$$
\begin{aligned}
& \varphi_{1}(r)=\cos (2 \pi r), \varphi_{2}(r)=\sin (2 \pi r), \varphi_{3}(r)=\cos (4 \pi r), \\
& \varphi_{4}(r)=\sin (4 \pi r), \varphi_{5}(r)=1, \varphi_{6}(r)=r, \varphi_{7}(r)=r^{2}
\end{aligned}
$$

with $r=t / T$. Note that the $\widehat{\tau}_{2}$ statistic is in essence the KPSS statistic, albeit with a different set of residuals. 
To see why Park and Hahn's (1999) approach may be useful to detect Markov switchingtype behavior, note that Park and Hahn (1999) assume that the elements of $\beta_{t}$ are of the form $\varphi(t / T)$, where $\varphi(r)$ has a Fourier flexible functional form. Let

$$
\beta_{t}^{P H}=\xi_{0}+\sum_{i} \xi_{i} r^{i}+\sum_{j} \xi_{j} \widetilde{\varphi}_{j}(r)
$$

where the $\xi^{\prime} s$ are the Fourier coefficients and $\widetilde{\varphi}_{j}(r)$ are the trigonometric functions, and let $\beta_{t}^{M S}=\beta_{0}+\beta_{1} S_{t}$, where $\beta_{1}>0$ and $\left\{S_{t}\right\}$ is a first-order Markov chain. Given any metric, the distance between $\beta_{t}^{P H}$ and $\beta_{t}^{M S}$ is not trivial as it depends, essentially, on the magnitude of the jump, $\beta_{1}$, and on the periodicity of the trigonometric functions, $K$. Clearly, $\beta_{t}^{P H}$ and $\beta_{q}^{M S}$ are uncorrelated for all $t, q$. Moreover, the bounds are given by $\bar{\beta}^{M S}=\beta_{0}+\beta_{1}$ and $\underline{\beta}^{M S}=\beta_{0}$ and, on the other hand,

$$
\begin{aligned}
\bar{\beta}^{P H} & =\max _{t} \beta_{t}^{P H} \leq \xi_{0}+\sum_{i} \xi_{i}+\sum_{j}\left|\xi_{j}\right| \\
\bar{\beta}^{P H} & =\min _{t} \beta_{t}^{P H} \geq \xi_{0}-\sum_{j}\left|\xi_{j}\right| .
\end{aligned}
$$

Hence, for $\sum_{j}\left|\xi_{j}\right|$ close to zero, the bounds will coincide when $\beta_{0} \approx \xi_{0}$ (corresponding to the case of standard cointegration) and $\beta_{1} \approx \sum_{i} \xi_{i}$.

\section{The Stock Price-Dividends Relationship}

\subsection{The Present Value model}

Consider the simple condition linking real stock prices $\left(P_{t}\right)$ and end-of-period dividends $\left(D_{t}\right)$

$$
P_{t}=e^{-r} E_{t}\left(D_{t}+P_{t+1}\right)
$$

where the real interest rate $r$ is assumed to be constant and $E_{t}$ denotes the conditional expectation at time $t$. A particular solution of the above stochastic difference equation is given by the present value relation

$$
P_{t}^{p v}=\sum_{s=t}^{\infty} e_{t}^{-r(s-t+1)} E_{t} D_{s},
$$

in which a stock price is equal to the present discounted value of expected future dividends ${ }^{2}$.

Several authors have noted, however, that, for certain periods, the evolution of stock prices appears to be disconnected and far more volatile than the underlying fundamental relationship (9), see LeRoy and Porter (1981) and Shiller (1981), for example. The unprecedented recent swings in stock prices (steady rise at the end of the last century and subsequent fall) has given impetus to a renewed interest in the present value specification. Bubbles, fads, noise traders or time varying discount factors have been proposed, but are not entirely successful in explaining the extent of the deviations from fundamentals (see Flood and Garber, 1980, Campbell and Shiller, 1988 and West, 1988 inter alia).

\footnotetext{
${ }^{2}$ This will form a unique solution by applying the transversality condition $\lim _{s \rightarrow \infty} e^{-r s} E_{t}\left(P_{s}\right)=0$.
} 
It has been extensively documented that stock prices and dividends appear to be nonstationary and, hence, (9) implies that these variables should be cointegrated. However, very few studies explicitly test the existence of a long run relationship between stock prices and dividends. When they do (Campbell and Shiller, 1987 and Kanas, 2003, for example), standard cointegration tests do not validate the cointegration hypothesis, which implicitly supports the 'rational' bubbles hypothesis. Some authors have instead argued that the pricedividend relationship exhibits fractional cointegration, resulting from the high persistence of temporary deviations from the long run equilibrium (see Caporale and Gil-Alana, 2004, for example).

Other explanations have looked at potential nonlinearities in the price-dividend relationship. Asymmetric dynamics can arise due to transaction costs, such that small deviations occur if the benefits from trading are not outweighed by the costs of trade, but larger deviations will be arbitraged out. On the other hand, recent behavioural finance models suggest that the actions of traders differ between bull and bear markets, e.g., traders may tend to overreact to good news in rising markets and trend-chase prices, while exhibiting a more conservative behaviour in falling markets (see Barberis and Thaler, 2003 for a recent survey). Non-linear specifications such as threshold or smooth-transition cointegration models have been used to detect these nonlinearities (see McMillan, 2004 and Bohl and Siklos, 2004, for example).

An alternative, but related, explanation focus on regime shifts in the dividends process, reflecting different phases in asset markets, which account for a substantial part of stock prices behavior. Indeed, Markov switching models have been extensively (and successfully) used to characterize and account for regime changes that typically occur in financial time series, see Bonomo and Garcia (1994), Schaller and Van Norden (1997), Driffill and Sola (1998), Psaradakis, Sola and Spagnolo (2004) and Sarno and Valente (2005), for example.

However, most of this literature focus on explaining asymmetries in the deviations from the long run equilibrium. We note instead that changes in expectations regarding dividends (following persistent shocks to output or productivity, say) or shifts in the dividend process itself (reflecting business cycle conditions) implies that the present value relationship is subject to regime shifts. Thus, we consider the cointegration counterpart of the framework discussed in Driffill and Sola (1998), in which deviations from stock prices fundamentals are explained by allowing the dividends process, as well as the present value relationship, to switch between two regimes.

To see this, assume, as in Froot and Obstfeld (1991), that log dividends $\left(d_{t}\right)$ follow a random walk

$$
d_{t+1}=d_{t}+\mu+\xi_{t+1}
$$

with trend growth $\mu$ and $\xi_{t}$ normally distributed with zero mean and variance $\sigma^{2}$. If dividends at $t$ are known, then the stock price is proportional to dividends

$$
P_{t}=\beta D_{t}
$$

with $\beta=\left(e^{r}-e^{\mu+\sigma^{2} / 2}\right)^{-1}$. As can be seen, $\beta$ contains several elements that can be thought of as being time-varying, including changes in the real interest rate $r$, shifts in dividends growth $\mu$ or periods when market volatility $\sigma$ changes. 
To capture this, we allow for switching behaviour in the log dividends process by specifying a Markov switching model as in Bonomo and Garcia (1994) and Driffill and Sola (1998) such that

$$
d_{t+1}=d_{t}+\mu_{0}\left(1-S_{t+1}\right)+\mu_{1} S_{t+1}+\left[\sigma_{0}\left(1-S_{t+1}\right)+\sigma_{1} S_{t+1}\right] \xi_{t+1}
$$

where $\left\{S_{t}\right\}$ is a homogeneous first-order Markov chain on $\{0,1\}$, with transition matrix $P=\left(p_{i j}\right)$, where $p_{i j}=\operatorname{Pr}\left(S_{t+1}=j \mid S_{t}=i\right), i, j \in S$. This then implies that stock prices are, as before, proportional to the current dividend, but with the factor of proportionality depending on the regime operative at time $t$, that is, $P_{t}=\beta_{0} D_{t}$ when $S_{t}=0$ and $P_{t}=\beta_{1} D_{t}$ when $S_{t}=0$, with the $\beta_{0}$ and $\beta_{1}$ satisfying

$$
\begin{aligned}
& \beta_{0}=\left(e^{r}-p_{00} \beta_{0} e^{\mu_{0}+\sigma_{0}^{2} / 2}\right)^{-1} \\
& \beta_{1}=\left(e^{r}-p_{11} \beta_{1} e^{\mu_{1}+\sigma_{1}^{2} / 2}\right)^{-1}
\end{aligned}
$$

see Driffill and Sola $(1998)^{3}$. Thus, unlike most of the previous literature, we introduce flexibility in the canonical present value model by explicitly allowing for shifts in the discount factor term defining the long run price-dividend relationship.

Note that the Markov switching setup for the stock price-dividend relationship is able to detect the type of nonlinearities mentioned above and has the advantage of also being consistent with the presence of rational bubbles, as discussed in Hall, Psaradakis and Sola (1999) and Fukuta (2002). Moreover, a Markov switching model is able to capture the longmemory fractional linear model features reported elsewhere (see Gabriel and Martins, 2004, for example).

From the economic point of view, we have established how Markov switching can arise in the price-dividends long run relationship, as it is not credible that the path taken by stock prices is such that there is, for all times, an increasing discrepancy between stock prices and fundamentals. From a methodological perspective, it is useful to ascertain whether or not the behaviour of tests on cointegration between stock prices and dividends is distorted by stochastic structural breaks that are unaccounted for and nonlinearities induced by this specification. Thus, we first consider the empirical evidence on the magnitude of potential shifts in $\beta$ and we subsequently analyse the performance of the tests described in section 2 .

\subsection{An empirical illustration}

To illustrate empirically the points discussed above, we look at data on stock prices and dividends for the US, the UK and Sweden ${ }^{4}$. US data has been extensively studied in the literature, mainly because data covering such a long span is readily available. The UK and Sweden cases (countries for which long run annual datasets have been constructed and are

\footnotetext{
${ }^{3}$ These authors specify this model in terms of the price-dividend ratio and therefore do not explicitly analyse cointegration between $P_{t}$ and $D_{t}$.

${ }^{4}$ US data (from 1900 to 1996) is available for Robert Shiller's webpage (www.econ.yale.edu/ shiller), where stock prices are January values for the Standard and Poor Composite Index, dividends are year-averages and both series are deflated by January values of the producer price index. UK and Swedish data (1918-1996) are taken from Campbell (1999), available from John Campbell's webpage (www.economics.harvard.edu/faculty/campbell) and the corresponding CPI is used to deflate the series. Following Psaradakis et al. (2004) and several other authors, we do not include the latest available sampling period, as the deviations from the implied relationship are unusually large and persistent, albeit temporary.
} 
available) have been studied in a unit roots/cointegration setting before, but with quarterly data only, covering a much shorter period (usually from 1960 onwards). Thus, it is an interesting empirical exercise to analyse these two cases and contrast them with the well known US case.

Figure 1 shows the series in real terms, from which the abrupt changes in the time path of the variables are noticeable for the three countries. This is particularly true in the latter part of the sample, namely for the UK and the US. Table 1 reports the results from cointegration tests, as well as DOLS estimates of the cointegrating relationship $P_{t}=\beta D_{t}+u_{t}{ }^{5}$. All tests for the null hypothesis of no cointegration fail to reject in the US case, which is consistent with previous results in the literature. There is strong evidence of a long run relationship for UK data, but results are mixed for Sweden. On the other hand, the KPSS-type test $(M L S)$ of McCabe et al. (1997) does not reject the existence of a (stable) long-run relationship between the two series for the UK and US, but rejects cointegration for Sweden.

The reason for the results against cointegration may be that the errors of the cointegrating regression capture unaccounted breaks and thus exhibit non-stationary behavior. Thus, we resort to the tests of Gregory and Hansen (1996), which are designed to be robust with respect to a regime shift in the cointegrating vector. These point to the existence of a long run relationship in the three countries, albeit with a potential structural break (with the exception of the $G H-A D F$ for the US).

To complement these tests, we use the Park-Hahn procedures. They show that there is substantial evidence of a time-varying cointegration vector, namely for Sweden and the US. Indeed, all tests reject the null of a stable long run relationship (except the $\widehat{\tau}_{1}$ with $n=1$ for the US), while only $\widehat{\tau}_{2}$ rejects in the case of the UK. Furthermore, assuming a time-varying long-run relationship specification $P_{t}=\beta_{t} D_{t}+u_{t}$ between prices and dividends, we can estimate the time-varying long run coefficient $\beta_{t}$, as in Park and Hahn (1999). In Figures 2 to 4 we present the sequences $\widehat{\beta}_{\kappa, t}$ for each country, with $\varphi_{i}(r), i=1, \ldots, 7$, defined above. This procedure is clearly picking up the 'dot.com' bubble at the end of sample in the three countries and while there appears to be evidence of swings in the cointegration vector, these are of different magnitudes in each case. The shifts are much less pronounced for the UK, with $\beta$ ranging from approximately 20 to 24 , which is consistent with the all the tests in Table 1 (including the $\widehat{\tau}_{i}$ tests). For Sweden and the US, changes are more pronounced, though the pattern of shifts is not systematic.

The Park and Hahn (1999) approach is useful in capturing the statistical features of the price-dividend relationship, but provides little guidance as a test for the theoretical aspects of the present value model. A statistical framework that is able to capture the time-varying nature of the present value model and, in addition, is more easily linked with the theory is the Markov switching approach, as discussed above. Thus, we now estimate the bivariate system linking the log dividends process with the present value relationship as in Driffill and Sola (1998), with the cointegrating parameter being subject to discrete changes. More specifically,

\footnotetext{
${ }^{5}$ The number of leads and lags for DOLS was determined using the Akaike information criterion. Note that there are no efficiency losses in pursuing a single-equation route when compared to multi-equation methods, as we are studying a bivariate relationship with potentially a single cointegration vector.
} 
we consider the following model:

$$
\begin{aligned}
& \left.\left.P_{t}=\left\{\beta_{0}+\left(\beta_{1}-\beta_{0}\right) S_{t}\right)\right\} D_{t}+\left\{\theta_{0}+\left(\theta_{1}-\theta_{0}\right) S_{t}\right)\right\} v_{t}, \quad\left\{v_{t}\right\} \stackrel{\mathrm{iid}}{\sim} N(0,1) \\
& \left.d_{t}=\mu_{0}+\left(\mu_{1}-\mu_{0}\right) S_{t}+d_{t-1}+\left\{\sigma_{0}+\left(\sigma_{1}-\sigma_{0}\right) S_{t}\right)\right\} u_{t}, \quad\left\{u_{t}\right\} \stackrel{\mathrm{iid}}{\sim} N(0,1),
\end{aligned}
$$

with $\left\{S_{t}\right\}$ defined as before. Note that (15) is specified as a standard cointegrating regression, instead of an implicitly cointegrated, ratio-type formulation (cf. Driffill and Sola, 1998, Eq. (16) and Appendix A for details on the estimation algorithm). Also, note that the system (15)-(16) is estimated simultaneously, with the same Markov chain driving changes in both the price-dividend equation and the log dividends process, with $r$ in (13)-(14) set at the sample average gross real return in each case.

No meaningful estimates of the parameters in (15)-(16) were obtained for UK data, however, again in accordance with the results discussed above, supporting a stable, linear relationship. The maximum likelihood estimates of (15)-(16) with Swedish and US are reported in Table 2 . In the regime 0 , we have a low growth/high volatility state in the dividends process, with cointegration vector $\left[1,-\beta_{0}\right]$, with $\hat{\beta}_{0}^{\text {Sweden }}=22.908$ and $\hat{\beta}_{0}^{U S}=19.367$, while regime 1 corresponds to a high growth/low volatility regime with $\left[1,-\beta_{1}\right]$, with $\hat{\beta}_{1}^{\text {Sweden }}=42.146$ and $\hat{\beta}_{1}^{U S}=30.088$. The probabilities of staying at each regime are high, indicating persistent regimes. These estimates contrast with the results in Table 1 for the "invariant" model, where $\hat{\beta}^{\text {Sweden }}=29.195$ and $\hat{\beta}^{U S}=25.353$, which is approximately the average of the two regimes identified in Table 2 . Also notice that the variances are significantly different in the two regimes.

The results are remarkably similar to those obtained in Driffill and Sola (1998), in that regime switching seems to provide a good explanation for the dynamics of the price-dividend relationship, at least for Sweden and the US. However, there is no direct way of testing for Markov switching cointegration. In fact, a researcher using the usual statistical tools would find conflicting evidence concerning the existence of cointegration between stock prices and dividends. It would be interesting to ascertain wether the tests discussed in section 2 are robust in a Markov switching setting. Thus, in what follows, we attempt to characterize the behavior of residual-based cointegration tests, by means of Monte Carlo simulations, assuming that the long run relationship is subject to Markov regime changes, considering empirically plausible parameterizations.

\section{Monte Carlo Analysis}

\subsection{Experimental Design and Simulation}

In our experiments, we consider Markov switching cointegration, as defined in Hall et al. (1997), where long-run parameters switch between different cointegrating regimes. Following the previous section, the DGP is specified as

$$
\begin{aligned}
& y_{t}=\left(\beta_{0}+\beta_{1} S_{t}\right) x_{t}+\left(\sigma_{0}+\sigma_{1} S_{t}\right) u_{t}, \\
& x_{t}=x_{t-1}+\varsigma_{t}, \quad t=1, \ldots, T,
\end{aligned}
$$

where $S_{t}$ is a binary random variable in $S=\{0,1\}$, defined as before, indicating the unobserved cointegrating regime at date $t$. 
Furthermore, it is assumed that $\left\{S_{t}\right\}$ is independent of the $I(0)$ processes $\left\{u_{t}\right\}$ and $\left\{\varsigma_{t}\right\}$. Hence, the cointegrating equation undergoes discrete shifts governed by the Markov chain $\left\{S_{t}\right\}$, with the cointegrating vector changing stochastically between $\left(1,-\beta_{0}\right)$ and $\left(1,-\beta_{0}-\beta_{1}\right)$, and $u_{t}$ representing the extent to which the system is out of long-run equilibrium.

For simplicity, we assume that $x_{t}$ has no intercept, which is consistent with the present value model (9) and the empirical results in section 3. Concerning the magnitude of the breaks in the coefficients, we fix $\beta_{0}=1$ for the relevant cases and let $\beta_{1}$ take on the values $\{0.5,1\}$. Thus, our design encompasses the relative magnitude of the breaks found in the empirical estimations of the previous section. In addition, the variance of the errors is also allowed to switch between regimes, so that $\sigma_{0}=1$ and $\sigma_{1} \in\{0,1\}$.

The model in (17)-(18) is very flexible and it encompasses the regime-shift models discussed by Gregory and Hansen (1996), which are obtained when $p_{11}=1$ or $p_{00}=1$. This specification also allows for a wide range of regime changes, depending on the values of the transition probabilities. In our simulations, we take $\left(p_{00}, p_{11}\right) \in\{(0.98,0.98),(0.95,0.95),(0.95,0.9)\}$. The first pair of transition probabilities $\left(p_{00}, p_{11}\right)=(0.98,0.98)$ implies highly persistent regimes, the average duration of each regime being 50 time periods. The probabilities $\left(p_{00}, p_{11}\right)=(0.95,0.95)$ imply less persistence, with an average regime duration of 20 time periods. Finally, the probabilities $\left(p_{00}, p_{11}\right)=(0.95,0.9)$ allow for asymmetric persistence, the mean duration of two regimes being 20 and 10 time periods. These values for the transition probabilities seem sensible, as we may expect some breaks to occur in a long run relationship, though not frequently.

To get an insight into differences in performance caused by the presence of regime shifts, a benchmark model with no regime switching is also considered. For every DGP, the errors $\left\{u_{t}\right\}$ are generated as an autoregressive process $u_{t}=\rho u_{t-1}+\varepsilon_{t}$, where $\rho \in\{0,0.75,1\}$ and $\left\{\left(\varepsilon_{t}, \varsigma_{t}\right)^{\prime}\right\} \stackrel{\text { iid }}{\sim} N\left(0, I_{2}\right)$. The selected sample sizes are $T=100$ and $T=200$. In order to attenuate the effect of initial values, $50+T$ artificial observations are generated in each replication (setting $x_{0}=u_{0}=0$ ), but the first 50 observations are discarded. In all experiments, the number of replications is 10000 .

It is worth noting that we allow for regime shifts under the hypothesis of no cointegration in our experiments, a case which has not been considered previously and is very seldom taken into account in applied work. Nevertheless, this is in line with recent research on unit roots and structural breaks reviewed in the introduction.

\subsection{Numerical Results}

In Tables 3-5, we record rejection frequencies for the various tests at the $5 \%$ level of significance. Figures in parentheses are the size-corrected power of null-of-no-cointegration (NNC) tests, the correction being based on the corresponding results with $\rho=1$ in each table. Given the way the DGP is parameterized, it is not clear which value for $\rho$ should be used under the null hypothesis of cointegration to obtain size-adjusted powers for the $M L S$ and Park-Hahn tests, so such results will not be presented for this type of tests.

Table 3 summarizes results from earlier studies for a model with no regime switching (cf. Gregory and Hansen, 1996, Table 2). For the model with no intercept, the ADF, GH-ADF and $Z_{\alpha}$ tests reject the null of no cointegration more often than they should. The $G H-Z_{\alpha}$ 
test tends to be slightly biased towards the null when $T=100$, while the $M L S$ test display reasonable Type-I error probabilities, at least for $\rho=0$. In terms of power, standard tests perform better and are less affected by autocorrelation.

Tables 4 and 5 present the results when the cointegrating vector is allowed to switch between different regimes. Instead of discussing the results for each set of experiments, perhaps it is more interesting to highlight some general common features of the results (regardless the particular model under study), which help to answer the questions posed in the end of the previous section. Firstly, it is clear that, independently of other parameter values, as the size of the break increases, both the power and size performance of all tests worsens. The problem seems to affect standard tests to a larger extent than $G H$-type tests, at least in terms of their ability to detect cointegration. The $M L S$ test is more affected in terms of level distortions than in terms of power loss, which is consistent with the results in Lee et al. (1997). It should be mentioned, however, that for a smaller break $\left(\beta_{1}=0.5\right)$ all tests perform reasonably well. As for the Park-Hahn tests, the $\widehat{\tau}_{1}$ tests behaves quite well, with power improving with the size of the break, whereas the $\widehat{\tau}_{2}$ is clearly unable to detect Markov switching cointegration, with power peaking only at $7 \%$ for $T=100$ and $\beta_{1}=0.5$.

On the other hand, changes in variance have ambiguous effects. A mild increase in the rejection frequencies under the null of NNC tests is accompanied by slightly higher nominal power, while both power and size distortions decrease for the Park-Hahn and $M L S$ tests. If we consider size-adjusted power, we observe that it stays very much the same, the gains being only marginal. Although this somehow contradicts the results in Hamori and Tokihisa (1997) and Kim et al. (2002) for univariate series and single deterministic breaks, it is more in accordance with Nelson et al. (2001). Note that, in our case, it is not possible to distinguish between upward shifts or downward shifts in variance (unless only one switch in regime occurs), since the relationship is switching between two states at unknown timings. Therefore, we may expect an "averaging" effect to be taking place, in terms of types of change in variances, which does not have a very dramatic impact on the performance of the tests.

Thirdly, increasing the size of the sample does not always have a positive impact on the small-sample properties of the tests, especially when there is no autocorrelation (although significant improvements occur for $\rho=0.75$ ). This is not surprising, since, on one hand, we should expect some improvements due to the longer sample length, but, on the other hand, this is counteracted by the fact that the number of breaks will increase, even in the case of relatively persistent regimes. Higher power is attained occasionally when the sample size is 100, except for the $M L S$ test, again confirming the results in Lee et al. (1997). However, it is clear that, in general, the estimated Type-I error probabilities for both types of tests diverge from the nominal value of $5 \%$ as $T$ grows, and the tendency is aggravated for larger shifts, quite severely in the case of the $M L S$ test with $\rho=0$. As before, $\widehat{\tau}_{2}$ performs badly for larger $T$, but $\widehat{\tau}_{1}$ improves its performance.

Moving next to the combined effects of regime shifts and autocorrelation, it is interesting to notice that the overrejection tendency of the $M L S$ test is attenuated when $\rho=0.75$, while the power of the ADF improves slightly. This may have to do with the fact that these tests are correcting for autocorrelation parametrically (as discussed in sections 2.1 and 2.3) and 
that the correction is being more effective for this structure of serial correlation ${ }^{6}$. On the other hand, autocorrelation in the errors affects the power of the other NNC tests, especially $G H$ tests. Nevertheless, this becomes less problematic as the sample size grows. In the case of the time-varying statistic $\widehat{\tau}_{1}$, higher autocorrelation induces a slight decrease in power.

Concerning the persistence of cointegration regimes, even though the number of breaks is larger when the transition probabilities decrease from 0.98 to 0.95 , the degree of autocorrelation is typically smaller. Thus, the simulations show that standard tests do a better job at rejecting a false null hypothesis of no cointegration. On the other hand, Gregory-Hansen tests perform better when the transition probabilities are 0.98 , probably because, being robust to a single break, they are able to cope better with the smaller number of shifts. Still, the effects of more breaks become apparent in the excessive frequency of rejections of the null of no cointegration. Despite slight improvements in power, this is also the case when there is asymmetry in the regimes $\left(p_{00}=0.95, p_{11}=0.9\right)$, since the autocorrelation function of the errors is a decreasing function of $\left|p_{00}-p_{11}\right|$ (see also Nelson et al., 2001, who discuss similar implications for the univariate case). As for the $M L S$ and Park-Hahn tests, the converse situation takes place: more breaks produce a slight decrease in the estimated power.

Finally, a word on the relative performance of the tests. Firstly, as the simulations make clear, Phillips-Ouliaris-type tests are superior to ADF-type tests in terms of (nominal and size-adjusted) power, although they are more liberal in general. Secondly, there may be considerable advantages in using robust tests, especially when autocorrelation in the errors is present. Within this class of tests, the $G H-Z_{\alpha}$ version seems to be the most well-balanced in terms of power and size. Turning to the $M L S$ test, although its power remains reasonable across DGP's, the problem lies in the excessive number of rejections of the null of cointegration, when the DGP is in fact cointegrated. This evidence suggests that this test may, in some circumstances, behave as structural change test rather than a cointegration test, since it also has power against omitted structural change, as discussed in section 2.3. Regarding the procedures for time-varying cointegration, the $\widehat{\tau}_{1}$ statistic performs reasonably well, particularly when we allow for a large number of superfluous trend terms $(n)$. This suggests that employing this procedure can be a robust and flexible way to detect sudden shifts in a long run relationship.

As for the $\widehat{\tau}_{2}$, it is of little use in this setup, since the simulation results suggest that $\widehat{\tau}_{2} \stackrel{p}{\rightarrow} 0$, as $T \rightarrow \infty$. Therefore, we conjecture that most probably there is a constant $\gamma>0$ such that $T^{\gamma} \widehat{\tau}_{2} \equiv \widehat{\tau}_{2}^{*}=O_{p}(1)$, under the Markov switching model. Deriving such constant $\gamma$ and the respective limiting law is not trivial and is left for future research. This seems to be an important topic, as it would lead to a test for Markov switching cointegration by means of a well-known test statistic (KPSS). Nevertheless, we conducted a simple simulation exercise to infer on the value of $\gamma$. Using the Monte Carlo setup at the bottom of Table $5\left(T=200, p_{i i}=0.95\right.$ and $\left.\rho=0\right)$, we tried a grid of values for $\gamma$ ranging between 0 and 2 to find an approximate value for $\gamma$ such that $P\left(T^{\gamma} \widehat{\tau}_{2}<0.16\right)=0.95$, where 0.16 is the $5 \%$ asymptotic critical value for the test $\widehat{\tau}_{2}$. We found $\gamma$ to equal 1.014, which suggests that maybe $T \widehat{\tau}_{2}=O_{p}(1)$, under the Markov switching model.

\footnotetext{
${ }^{6}$ Indeed, additional experiments not reported here show that if a non-parametric version of the KPSS statistic is used in this context, the effect of autocorrelation increases monotonically, as usual.
} 


\section{Conclusion}

In this paper, we have investigated the finite-sample properties of cointegration tests when the cointegrating vector is subject to Markov regime shifts. We motivate our study by considering how Markov switching may arise in a long run present value model of stock prices and dividends. In our empirical analysis, we show that there is substantial evidence of shifts in the long run price-dividend relationship for the US and Sweden, though not for the UK.

Our subsequent experiments reveal that a combination of high regime persistence and large magnitude of shifts can affect the ability of tests to detect cointegration, but not to a great extent. Furthermore, Markov-type heteroskedasticity in the equilibrium errors has an insignificant impact on the performance of the tests. We also conclude that the GregoryHansen tests, namely the $G H-Z_{\alpha}$ procedure, displays a reasonable behaviour, in particular when less frequent breaks occur, which is likely to be empirically more relevant in the study of long run relationships. Similarly, the time-varying cointegration procedure $\widehat{\tau}_{1}$ performs well, but with no apparent advantage over the standard tests analyzed here.

It is important, however, to stress that a researcher should be cautious in interpreting the results of KPSS-type tests. In fact, the $M L S$ statistic also has power against parameter instability. This means that a rejection can occur either because there is no long run relationship, or because there is cointegration with potential structural changes. One can conclude that a standard cointegration model (assuming parameter stability) is not supported by the data, but further testing may be needed to clarify this rejection (lack of cointegration or parameter instability). Our study suggests that a suitable normalization of these statistics may lead to an appropriate testing procedure for this type of DGP.

Finally, our results seem to suggest that if the underlying relationship between stock prices and dividends were to follow a two-state Markov switching process, the usual tests would be able to reject the null of no cointegration. Indeed, our simulation study, based on a plausible parameterization similar to the price-dividend relationship, shows that standard cointegration tests appear to be quite robust in detecting the existence of a long run relationship, even in the case where it follows a non-linear Markovian process. Previous literature on structural breaks and cointegration (Gregory et al., 1996, Gregory and Hansen, 1996, Campos et al., 1996, etc.) focused on cases when there is a single deterministic, permanent shift. When more breaks occur, as in our setup, the performance of the usual residual-based tests appears to be reasonable. As we noted before, the higher the persistence of the regime shifts (i.e., the closer we approach the one-off shift case), the more likely it is for the residuals to resemble a unit root process. Thus, more frequent switching is less problematic for the tests' behaviour.

Note that we focused our analysis on a DGP with no intercept, which is in accordance with the theoretical present value model. It is possible that for more general cases, in which the intercept or trend terms are subject to shifts, the performance of the tests may worsen, in line with previous literature. It might be the case that researchers need to look elsewhere in order to explain the large deviations of stock prices from fundamentals. For instance, while simpler Markov switching processes are, in practice, indistinguishable from market bubbles, these models are not able to capture the 'dot-com' bubble of 1995-2001, thus suggesting the 
existence of a more complex dynamic structure between stock prices and dividends.

\section{References}

[1] Andrews, D. W. K. and Monahan, J. C. (1992), An improved heteroskedasticity and autocorrelation consistent covariance matrix estimator, Econometrica, 60, 953-966.

[2] Barberis, N. and Thaler, R. (2003), "A Survey of Behavioral Finance", in Constantinides, G., Harris, M., Stultz, R. (Eds.), Handbook of the Economics of Finance, Vol. 1, chapter 18, 1053-1128, Elsevier North-Holland, Amsterdam.

[3] Bierens, H. and Martins, L. F. (2010), Time Varying Cointegration, Econometric Theory, forthcoming.

[4] Bohl, M. T. and Siklos, P. L. (2004), The present value model of U.S. stock prices redux: a new testing strategy and some evidence, Quarterly Review of Economics and Finance, $44,208-223$.

[5] Bonomo, M. and Garcia, R. (1994), Can a well-fitted equilibrium asset-pricing model produce mean reversion?, Journal of Applied Econometrics, 9, 19-29.

[6] Breitung, J. (2001), Rank Tests for Nonlinear Cointegration, Journal of Business and Economic Statistics, 19, 331-340.

[7] Campbell, J. Y. (1999), "Asset prices, consumption, and the business cycle", Handbook of Macroeconomics, in Taylor, J. B. and Woodford, M. (ed.), Vol. 1, chapter 19, 12311303, Elsevier.

[8] Campbell, J. Y. and Shiller, R. J. (1987), Cointegration and Tests of Present Value Models, Journal of Political Economy, 95, 1062-1088.

[9] Campbell, J. Y. and Shiller, R. J. (1988), The dividend-price ratio and the expectations of future dividends and discount factors, Review of Financial Studies, 1, 195-228.

[10] Campos, J., Ericsson, N. R. and Hendry, D. F. (1996), Cointegration tests in the presence of structural breaks, Journal of Econometrics, 70, 187-220.

[11] Caporale, G. M. and Gil-Alana, L. A. (2004), Fractional cointegration and tests of present value models, Review of Financial Economics, 13, 245-258.

[12] Driffill, J. and Sola, M. (1998), Intrinsic bubbles and regime-switching, Journal of Monetary Economics, 42, 357-373.

[13] Flood, R. P. and Garber, P. M. (1980), Market fundamentals versus price-level bubbles: the first tests, Journal of Political Economy, 88, 745-770.

[14] Froot, K. and Obstfeld, M. (1991), Intrinsic bubbles: the case of stock prices, American Economic Review, 81, 1189-1214.

[15] Fukuta, Y. (2002), A test for rational bubbles in stock prices, Empirical Economics, 27, 587-600. 
[16] Gabriel, V. J. and Martins, L. F. (2004), On the forecasting ability of ARFIMA models when infrequent breaks occur, Econometrics Journal, 7, 455-475.

[17] Granger, C. W. J. (2008), Non-Linear Models: Where Do We Go Next - Time Varying Parameter Models?, Studies in Nonlinear Dynamics \& Econometrics, 12, issue 3, Article 1.

[18] Gregory, A. W. and Hansen, B. E. (1996), Residual-based tests for cointegration in models with regime shifts, Journal of Econometrics, 70, 99-126.

[19] Gregory, A. W., Nason, J. M. and Watt, P. G. (1996), Testing for structural breaks in cointegrated relationships, Journal of Econometrics, 71, 321-341.

[20] Hall, S. G., Psaradakis, Z. and Sola, M. (1997), Cointegration and changes in regime: the Japanese consumption function, Journal of Applied Econometrics, 12, 151-168.

[21] Hall, S. G., Psaradakis, Z. and Sola, M. (1999), Detecting periodically collapsing bubbles: a Markov switching unit root test, Journal of Applied Econometrics, 14, 143-154.

[22] Hamori, S. and Tokihisa, A. (1997), Testing for a unit root in the presence of a variance shift, Economics Letters, 37, 245-253.

[23] Hansen, B. E. (1992), Tests for parameter instability in regressions with I(1) processes, Journal of Business and Economic Statistics, 10, 321-335.

[24] Harris, D. and Inder, B. (1994), A test of the null of cointegration, in C. Hargreaves (ed.), Non-stationary Time Series Analysis and Cointegration, Oxford University Press, Oxford, 133-152.

[25] Kanas, A. (2003), Non-linear cointegration between stock prices and dividends, Applied Economics Letters, 10, 401-405.

[26] Kim, T.-H., Leybourne, S. J. and Newbold, P. (2002), Unit root tests with a break in variance, Journal of Econometrics, 109, 365-387.

[27] Krolzig, H.-M. (1997), Statistical analysis of cointegrated VAR processes with Markovian shifts, manuscript, University of Oxford.

[28] Kwiatkowski, D., Phillips, P. C. B., Schmidt, P. and Shin, Y. (1992), Testing the null hypothesis of stationarity against the alternative of a unit root: how sure are we that economic time series have a unit root?, Journal of Econometrics, 54, 159-178.

[29] Lee, J., Huang, C. J. and Shin, Y. (1997), On stationarity tests in the presence of structural breaks, Economics Letters, 55, 165-172.

[30] LeRoy, S. H. and Porter, R. D. (1981), The present-value relation: tests based on implied variance bounds, Econometrica, 49, 555-574.

[31] Leybourne, S. J. and McCabe, B. P. M. (1999), Modified stationarity tests with datadependent model-selection rules, Journal of Business and Economic Statistics, 17, 264270. 
[32] Leybourne, S. J., Mills, T. C. and Newbold, P. (1998), Spurious rejections by DickeyFuller tests in the presence of a break under the null, Journal of Econometrics, 87, 191-203.

[33] Leybourne, S. J. and Newbold, P. (2000), Behavior of the standard and symmetric Dickey-Fuller-type tests when there is a break under the null hypothesis, Econometrics Journal, 3, 1-45.

[34] McCabe, B. P. M. and Leybourne, S. J. and Shin, Y. (1997), A parametric approach to testing for the null of cointegration, Journal of Time Series Analysis, 18, 395-413.

[35] McMillan, D. G. (2004), Nonlinear predictability of short-run deviations in UK stock market returns, Economics Letters, 84, 149-154.

[36] Nelson, C. R., Piger, J. and Zivot, E. (2001), Markov regime-switching and unit root tests, Journal of Business and Economic Statistics, 19, 404-415.

[37] Park, J. Y. and Hahn, S. B. (1999), Cointegrating Regressions with Time Varying Coefficients, Econometric Theory, 15, 664-703.

[38] Perron, P. (1989), The great crash, the oil-price shock, and the unit root hypothesis, Econometrica, 57, 1361-1401.

[39] Phillips, P. C. B. and Ouliaris, S. (1990), Asymptotic properties of residual-based tests for cointegration, Econometrica, 58, 165-193.

[40] Psaradakis, Z. (2001), Markov level shifts and the unit-root hypothesis, Econometrics Journal, 4, 226-242.

[41] Psaradakis, Z. (2002), On the asymptotic behaviour of unit-root tests in the presence of a Markov trend, Statistics and Probability Letters, 57, 101-109.

[42] Psaradakis, Z., Sola, M. and Spagnolo, F. (2004), On Markov Error-Correction Models, with an Application to Stock Prices and Dividends, Journal of Applied Econometrics, 19, 69-88.

[43] Saikkonen, P. (1991), Asymptotically efficient estimation of cointegrating regressions, Econometric Theory, 7, 1-21.

[44] Saikkonen, P and Choi, I. (2004), Cointegrating Smooth Transition Regressions, Econometric Theory, 20, 301-340.

[45] Sarno, L. and Valente, G. (2005), Modelling and Forecasting Stock Returns: Exploiting the Futures Market, Regime Shifts and International Spillovers, Journal of Applied Econometrics, 20, 345-376.

[46] Schaller, H. and Van Norden, S. (1997), Regime switching in stock markets returns, Applied Financial Economics, 7, 177-191.

[47] Shiller, R. J. (1981) Do stock prices move too much to be justified by subsequent changes in dividends?, American Economic Review, 71, 421-436. 
[48] Shin, Y. (1994), A residual-based test of the null of cointegration against the alternative of no cointegration, Econometric Theory, 10, 91-115.

[49] West, K. D. (1988), Bubbles, fads and stock price volatility tests: a partial evaluation, Journal of Finance, 43, 639-655. 
Table 1: Cointegration analysis

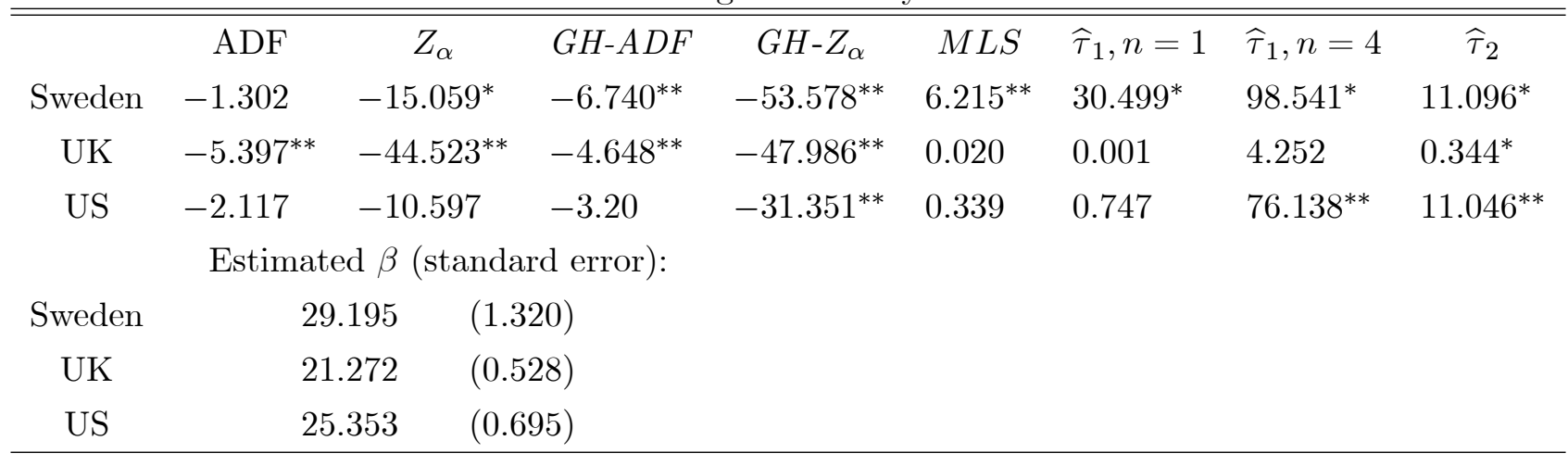

Note: ${ }^{* *}$ means rejection at the $5 \%$ significance level;.* means rejection at the $10 \%$ significance level

Table 2: Maximum likelihood estimates

\begin{tabular}{cccccccc}
\hline \hline Sweden & Eq. (15) & $\beta_{0}$ & $\beta_{1}$ & $\theta_{0}$ & $\theta_{1}$ & $p_{00}$ & $p_{11}$ \\
& & 22.908 & 42.146 & 0.0652 & 0.3152 & 0.9646 & 0.9958 \\
& & $(5.957)$ & $(7.329)$ & $(0.0131)$ & $(0.0385)$ & $(0.1694)$ & $(0.0351)$ \\
& Eq. (16) & $\mu_{0}$ & $\mu_{1}$ & $\sigma_{0}$ & $\sigma_{1}$ & & \\
& & -0.0034 & 0.0386 & 0.1587 & 0.1149 & & \\
\hline US & Eq. (15) & $\beta_{0}$ & $\beta_{1}$ & $\theta_{0}$ & $\theta_{1}$ & $p_{00}$ & $p_{11}$ \\
& & 19.367 & 30.088 & 0.1466 & 0.2995 & 0.9798 & 0.9843 \\
& & $(5.698)$ & $(5.709)$ & $(0.0192)$ & $(0.0635)$ & $(0.0376)$ & $(0.0422)$ \\
& Eq. (16) & $\mu_{0}$ & $\mu_{1}$ & $\sigma_{0}$ & $\sigma_{1}$ & & \\
& & -0.0014 & 0.0316 & 0.1513 & 0.0462 & & \\
& & $(0.0010)$ & $(0.0041)$ & $(0.0012)$ & $(0.0012)$ & & \\
\hline
\end{tabular}

Note: Standard errors are in parentheses. 
Table 3: Testing for cointegration with no regime shifts $(\beta=1)$

\begin{tabular}{lcccccc} 
& $T=100$ & \multicolumn{5}{c}{$T=200$} \\
\multicolumn{1}{c}{$\rho=$} & 0 & 0.75 & 1 & 0 & 0.75 & 1 \\
\hline ADF & 0.99 & 0.934 & 0.06 & 1.00 & 0.997 & 0.052 \\
& $(0.988)$ & $(0.921)$ & & $(1.00)$ & $(0.943)$ & \\
$Z_{\alpha}$ & 1.00 & 0.989 & 0.072 & 1.00 & 1.00 & 0.066 \\
& $(1.00)$ & $(0.973)$ & & $(1.00)$ & $(1.00)$ & \\
$G H-A D F$ & 0.978 & 0.741 & 0.066 & 0.999 & 0.975 & 0.06 \\
& $(0.97)$ & $(0.644)$ & & $(0.998)$ & $(0.972)$ & \\
$G H-Z_{\alpha}$ & 1.00 & 0.728 & 0.026 & 1.00 & 1.00 & 0.042 \\
& $(1.00)$ & $(0.855)$ & & $(1.00)$ & $(1.00)$ & \\
$M L S$ & 0.044 & 0.148 & 0.856 & 0.046 & 0.074 & 0.948 \\
\hline
\end{tabular}

Note: Size-adjusted power in parentheses 
Table 4 - Change in slope, no constant $\left(\beta_{1}=0.5\right)$

\begin{tabular}{|c|c|c|c|c|c|c|c|c|c|}
\hline \multirow[b]{2}{*}{$\rho=$} & \multicolumn{3}{|c|}{$p_{00}=p_{11}=0.98$} & \multicolumn{3}{|c|}{$p_{00}=p_{11}=0.95$} & \multicolumn{3}{|c|}{$p_{00}=0.95, p_{11}=0.9$} \\
\hline & 0 & 0.75 & 1 & 0 & 0.75 & 1 & 0 & 0.75 & 1 \\
\hline \multicolumn{10}{|l|}{$\beta_{1}=0.5, \sigma_{1}=0$} \\
\hline $\mathrm{ADF} \quad(T=100)$ & $\begin{array}{l}0.73 \\
(0.715)\end{array}$ & $\begin{array}{l}0.754 \\
(0.729)\end{array}$ & 0.06 & $\begin{array}{l}0.781 \\
(0.739)\end{array}$ & $\begin{array}{l}0.797 \\
(0.74)\end{array}$ & 0.069 & $\begin{array}{l}0.868 \\
(0.821)\end{array}$ & $\begin{array}{l}0.859 \\
(0.78)\end{array}$ & 0.079 \\
\hline$Z_{\alpha}$ & $\begin{array}{l}0.928 \\
(0.907)\end{array}$ & $\begin{array}{l}0.846 \\
(0.788)\end{array}$ & 0.083 & $\begin{array}{l}0.958 \\
(0.922)\end{array}$ & $\begin{array}{l}0.882 \\
(0.782)\end{array}$ & 0.099 & $\begin{array}{l}0.979 \\
(0.949)\end{array}$ & $\begin{array}{l}0.925 \\
(0.82)\end{array}$ & 0.113 \\
\hline$G H-A D F$ & $\begin{array}{l}0.909 \\
(0.897)\end{array}$ & $\begin{array}{c}0.64 \\
(0.556)\end{array}$ & 0.068 & $\begin{array}{l}0.863 \\
(0.838)\end{array}$ & $\begin{array}{l}0.614 \\
(0.521)\end{array}$ & 0.072 & $\begin{array}{l}0.888 \\
(0.851)\end{array}$ & $\begin{array}{l}0.665 \\
(0.545)\end{array}$ & 0.079 \\
\hline$G H-Z_{\alpha}$ & $\begin{array}{l}0.971 \\
(0.98)\end{array}$ & $\begin{array}{l}0.678 \\
(0.776)\end{array}$ & 0.03 & $\begin{array}{l}0.952 \\
(0.962)\end{array}$ & $\begin{array}{c}0.636 \\
(0.70)\end{array}$ & 0.035 & $\begin{array}{l}0.959 \\
(0.965)\end{array}$ & $\begin{array}{c}0.68 \\
(0.708)\end{array}$ & 0.045 \\
\hline$M L S$ & 0.334 & 0.231 & 0.836 & 0.304 & 0.21 & 0.814 & 0.214 & 0.178 & 0.81 \\
\hline$\widehat{\tau}_{1}, n=1$ & 0.515 & 0.462 & - & 0.472 & 0.429 & - & 0.388 & 0.356 & - \\
\hline$\widehat{\tau}_{1}, n=4$ & 0.788 & 0.775 & - & 0.803 & 0.767 & - & 0.717 & 0.666 & - \\
\hline$\widehat{\tau}_{2}$ & 0.069 & 0.065 & - & 0.004 & 0.003 & - & 0.011 & 0.009 & - \\
\hline $\mathrm{ADF} \quad(T=200)$ & $\begin{array}{l}0.676 \\
(0.661)\end{array}$ & $\begin{array}{l}0.846 \\
(0.837)\end{array}$ & 0.057 & $\begin{array}{l}0.902 \\
(0.839)\end{array}$ & $\begin{array}{c}0.95 \\
(0.907)\end{array}$ & 0.084 & $\begin{array}{l}0.962 \\
(0.908)\end{array}$ & $\begin{array}{l}0.979 \\
(0.936)\end{array}$ & 0.106 \\
\hline$Z_{\alpha}$ & $\begin{array}{c}0.93 \\
(0.886)\end{array}$ & $\begin{array}{l}0.921 \\
(0.864)\end{array}$ & 0.097 & $\begin{array}{l}0.991 \\
(0.96)\end{array}$ & $\begin{array}{l}0.992 \\
(0.942)\end{array}$ & 0.132 & $\begin{array}{l}0.999 \\
(0.986)\end{array}$ & $\begin{array}{l}0.999 \\
(0.974)\end{array}$ & 0.17 \\
\hline$G H-A D F$ & $\begin{array}{l}0.778 \\
(0.766)\end{array}$ & $\begin{array}{l}0.834 \\
(0.815)\end{array}$ & 0.058 & $\begin{array}{l}0.853 \\
(0.779)\end{array}$ & $\begin{array}{l}0.872 \\
(0.784)\end{array}$ & 0.095 & $\begin{array}{l}0.924 \\
(0.856)\end{array}$ & $\begin{array}{l}0.922 \\
(0.829)\end{array}$ & 0.118 \\
\hline$G H-Z_{\alpha}$ & $\begin{array}{l}0.953 \\
(0.954)\end{array}$ & $\begin{array}{l}0.896 \\
(0.89)\end{array}$ & 0.054 & $\begin{array}{l}0.982 \\
(0.962)\end{array}$ & $\begin{array}{l}0.948 \\
(0.90)\end{array}$ & 0.082 & $\begin{array}{l}0.996 \\
(0.979)\end{array}$ & $\begin{array}{l}0.979 \\
(0.921)\end{array}$ & 0.118 \\
\hline$M L S$ & 0.65 & 0.27 & 0.927 & 0.425 & 0.165 & 0.89 & 0.264 & 0.109 & 0.89 \\
\hline$\widehat{\tau}_{1}, n=1$ & 0.572 & 0.504 & - & 0.394 & 0.361 & - & 0.300 & 0.285 & - \\
\hline$\widehat{\tau}_{1}, n=4$ & 0.885 & 0.839 & - & 0.775 & 0.711 & - & 0.609 & 0.577 & - \\
\hline$\widehat{\tau}_{2}$ & 0.007 & 0.007 & - & 0.000 & 0.000 & - & 0.000 & 0.000 & - \\
\hline \multicolumn{10}{|l|}{$\beta_{1}=0.5, \sigma_{1}=1$} \\
\hline $\mathrm{ADF} \quad(T=100)$ & $\begin{array}{l}0.779 \\
(0.748)\end{array}$ & $\begin{array}{l}0.814 \\
(0.755)\end{array}$ & 0.072 & $\begin{array}{l}0.826 \\
(0.76)\end{array}$ & $\begin{array}{c}0.85 \\
(0.748)\end{array}$ & 0.103 & $\begin{array}{l}0.899 \\
(0.847)\end{array}$ & $\begin{array}{c}0.90 \\
(0.778)\end{array}$ & 0.112 \\
\hline$Z_{\alpha}$ & $\begin{array}{c}0.98 \\
(0.966)\end{array}$ & $\begin{array}{l}0.916 \\
(0.819)\end{array}$ & 0.108 & $\begin{array}{l}0.993 \\
(0.968)\end{array}$ & $\begin{array}{l}0.937 \\
(0.758)\end{array}$ & 0.148 & $\begin{array}{l}0.998 \\
(0.986)\end{array}$ & $\begin{array}{l}0.966 \\
(0.794)\end{array}$ & 0.174 \\
\hline$G H-A D F$ & $\begin{array}{l}0.917 \\
(0.902)\end{array}$ & $\begin{array}{l}0.685 \\
(0.528)\end{array}$ & 0.086 & $\begin{array}{l}0.886 \\
(0.847)\end{array}$ & $\begin{array}{l}0.667 \\
(0.476)\end{array}$ & 0.102 & $\begin{array}{c}0.92 \\
(0.884)\end{array}$ & $\begin{array}{l}0.719 \\
(0.481)\end{array}$ & 0.109 \\
\hline$G H-Z_{\alpha}$ & $\begin{array}{l}0.99 \\
(0.99)\end{array}$ & $\begin{array}{l}0.706 \\
(0.706)\end{array}$ & 0.05 & $\begin{array}{l}0.987 \\
(0.986)\end{array}$ & $\begin{array}{l}0.692 \\
(0.65)\end{array}$ & 0.06 & $\begin{array}{l}0.994 \\
(0.983)\end{array}$ & $\begin{array}{c}0.72 \\
(0.636)\end{array}$ & 0.071 \\
\hline$M L S$ & 0.287 & 0.211 & 0.797 & 0.248 & 0.192 & 0.753 & 0.158 & 0.152 & 0.753 \\
\hline$\widehat{\tau}_{1}, n=1$ & 0.460 & 0.435 & - & 0.425 & 0.405 & - & 0.339 & 0.357 & - \\
\hline$\widehat{\tau}_{1}, n=4$ & 0.732 & 0.777 & - & 0.755 & 0.754 & - & 0.647 & 0.705 & - \\
\hline$\widehat{\tau}_{2}$ & 0.000 & 0.000 & - & 0.000 & 0.000 & - & 0.000 & 0.000 & - \\
\hline $\operatorname{ADF} \quad(T=200)$ & $\begin{array}{l}0.738 \\
(0.678)\end{array}$ & $\begin{array}{l}0.912 \\
(0.876)\end{array}$ & 0.072 & $\begin{array}{l}0.914 \\
(0.814)\end{array}$ & $\begin{array}{l}0.971 \\
(0.899)\end{array}$ & 0.144 & $\begin{array}{l}0.973 \\
(0.909)\end{array}$ & $\begin{array}{l}0.988 \\
(0.933)\end{array}$ & 0.164 \\
\hline$Z_{\alpha}$ & $\begin{array}{l}0.981 \\
(0.95)\end{array}$ & $\begin{array}{l}0.975 \\
(0.918)\end{array}$ & 0.146 & $\begin{array}{l}0.989 \\
(0.972)\end{array}$ & $\begin{array}{l}0.997 \\
(0.923)\end{array}$ & 0.301 & $\begin{array}{l}1.00 \\
(0.992)\end{array}$ & $\begin{array}{l}1.00 \\
(0.962)\end{array}$ & 0.36 \\
\hline$G H-A D F$ & $\begin{array}{l}0.828 \\
(0.787)\end{array}$ & $\begin{array}{l}0.893 \\
(0.845)\end{array}$ & 0.084 & $\begin{array}{l}0.88 \\
(0.77)\end{array}$ & $\begin{array}{l}0.928 \\
(0.804)\end{array}$ & 0.137 & $\begin{array}{l}0.944 \\
(0.868)\end{array}$ & $\begin{array}{l}0.956 \\
(0.858)\end{array}$ & 0.152 \\
\hline$G H-Z_{\alpha}$ & $\begin{array}{l}0.989 \\
(0.986)\end{array}$ & $\begin{array}{l}0.957 \\
(0.924)\end{array}$ & 0.085 & $\begin{array}{l}0.997 \\
(0.989)\end{array}$ & $\begin{array}{l}0.981 \\
(0.911)\end{array}$ & 0.127 & $\begin{array}{l}1.00 \\
(0.996)\end{array}$ & $\begin{array}{l}0.994 \\
(0.94)\end{array}$ & 0.153 \\
\hline$M L S$ & 0.572 & 0.216 & 0.898 & 0.375 & 0.128 & 0.835 & 0.223 & 0.094 & 0.833 \\
\hline$\widehat{\tau}_{1}, n=1$ & 0.543 & 0.456 & - & 0.375 & 0.343 & - & 0.283 & 0.275 & - \\
\hline$\widehat{\tau}_{1}, n=4$ & 0.862 & 0.799 & - & 0.737 & 0.682 & - & 0.577 & 0.569 & - \\
\hline$\widehat{\tau}_{2}$ & 0.000 & 0.000 & - & 0.000 & 0.000 & - & 0.000 & 0.000 & - \\
\hline
\end{tabular}


Table 5 - Change in slope, no constant $\left(\beta_{1}=1\right)$

\begin{tabular}{|c|c|c|c|c|c|c|c|c|c|}
\hline \multirow[b]{2}{*}{$\rho=$} & \multicolumn{3}{|c|}{$p_{00}=p_{11}=0.98$} & \multicolumn{3}{|c|}{$p_{00}=p_{11}=0.95$} & \multicolumn{3}{|c|}{$p_{00}=0.95, p_{11}=0.9$} \\
\hline & 0 & 0.75 & 1 & 0 & 0.75 & 1 & 0 & 0.75 & 1 \\
\hline \multicolumn{10}{|l|}{$\beta_{1}=1, \sigma_{1}=0$} \\
\hline $\operatorname{ADF}(T=100)$ & $\begin{array}{c}0.62 \\
(0.597)\end{array}$ & $\begin{array}{l}0.575 \\
(0.546)\end{array}$ & 0.06 & $\begin{array}{l}0.678 \\
(0.58)\end{array}$ & $\begin{array}{l}0.641 \\
(0.521)\end{array}$ & 0.088 & $\begin{array}{l}0.795 \\
(0.685)\end{array}$ & $\begin{array}{l}0.753 \\
(0.602)\end{array}$ & 0.108 \\
\hline$Z_{\alpha}$ & $\begin{array}{l}0.766 \\
(0.708)\end{array}$ & $\begin{array}{l}0.712 \\
(0.709)\end{array}$ & 0.108 & $\begin{array}{l}0.817 \\
(0.656)\end{array}$ & $\begin{array}{l}0.77 \\
(0.533)\end{array}$ & 0.146 & $\begin{array}{l}0.914 \\
(0.725)\end{array}$ & $\begin{array}{l}0.876 \\
(0.575)\end{array}$ & 0.187 \\
\hline$G H-A D F$ & $\begin{array}{l}0.858 \\
(0.832)\end{array}$ & $\begin{array}{c}0.61 \\
(0.532)\end{array}$ & 0.071 & $\begin{array}{l}0.762 \\
(0.712)\end{array}$ & $\begin{array}{l}0.571 \\
(0.461)\end{array}$ & 0.09 & $\begin{array}{l}0.812 \\
(0.716)\end{array}$ & $\begin{array}{c}0.64 \\
(0.456)\end{array}$ & 0.101 \\
\hline$G H-Z_{\alpha}$ & $\begin{array}{l}0.912 \\
(0.916)\end{array}$ & $\begin{array}{c}0.681 \\
(0.70)\end{array}$ & 0.046 & $\begin{array}{l}0.829 \\
(0.817)\end{array}$ & $\begin{array}{c}0.606 \\
(0.57)\end{array}$ & 0.062 & $\begin{array}{l}0.865 \\
(0.818)\end{array}$ & $\begin{array}{l}0.67 \\
(0.555)\end{array}$ & 0.083 \\
\hline$M L S$ & 0.396 & 0.329 & 0.808 & 0.352 & 0.277 & 0.755 & 0.244 & 0.218 & 0.736 \\
\hline$\widehat{\tau}_{1}, n=1$ & 0.566 & 0.535 & - & 0.516 & 0.484 & - & 0.416 & 0.395 & - \\
\hline$\widehat{\tau}_{1}, n=4$ & 0.833 & 0.839 & - & 0.847 & 0.828 & - & 0.749 & 0.728 & - \\
\hline$\widehat{\tau}_{2}$ & 0.053 & 0.053 & - & 0.002 & 0.002 & - & 0.005 & 0.005 & - \\
\hline $\operatorname{ADF}(T=200)$ & $\begin{array}{c}0.57 \\
(0.506)\end{array}$ & $\begin{array}{c}0.67 \\
(0.608)\end{array}$ & 0.067 & $\begin{array}{l}0.849 \\
(0.628)\end{array}$ & $\begin{array}{l}0.875 \\
(0.648)\end{array}$ & 0.151 & $\begin{array}{l}0.945 \\
(0.734)\end{array}$ & $\begin{array}{l}0.952 \\
(0.73)\end{array}$ & 0.202 \\
\hline$Z_{\alpha}$ & $\begin{array}{l}0.758 \\
(0.623)\end{array}$ & $\begin{array}{l}0.772 \\
(0.61)\end{array}$ & 0.137 & $\begin{array}{l}0.956 \\
(0.688)\end{array}$ & $\begin{array}{l}0.957 \\
(0.65)\end{array}$ & 0.277 & $\begin{array}{l}0.991 \\
(0.784)\end{array}$ & $\begin{array}{l}0.994 \\
(0.711)\end{array}$ & 0.367 \\
\hline$G H-A D F$ & $\begin{array}{l}0.681 \\
(0.67)\end{array}$ & $\begin{array}{l}0.668 \\
(0.654)\end{array}$ & 0.054 & $\begin{array}{l}0.779 \\
(0.627)\end{array}$ & $\begin{array}{c}0.756 \\
(0.56)\end{array}$ & 0.126 & $\begin{array}{c}0.89 \\
(0.668)\end{array}$ & $\begin{array}{l}0.871 \\
(0.573)\end{array}$ & 0.189 \\
\hline$G H-Z_{\alpha}$ & $\begin{array}{l}0.851 \\
(0.812)\end{array}$ & $\begin{array}{l}0.796 \\
(0.728)\end{array}$ & 0.077 & $\begin{array}{l}0.919 \\
(0.77)\end{array}$ & $\begin{array}{l}0.88 \\
(0.635)\end{array}$ & 0.154 & $\begin{array}{l}0.975 \\
(0.792)\end{array}$ & $\begin{array}{l}0.958 \\
(0.633)\end{array}$ & 0.226 \\
\hline$M L S$ & 0.646 & 0.428 & 0.904 & 0.39 & 0.265 & 0.827 & 0.228 & 0.168 & 0.803 \\
\hline$\widehat{\tau}_{1}, n=1$ & 0.594 & 0.565 & - & 0.406 & 0.391 & - & 0.307 & 0.303 & - \\
\hline$\widehat{\tau}_{1}, n=4$ & 0.902 & 0.889 & - & 0.772 & 0.754 & - & 0.622 & 0.608 & - \\
\hline$\widehat{\tau}_{2}$ & 0.006 & 0.006 & - & 0.000 & 0.000 & - & 0.000 & 0.000 & - \\
\hline \multicolumn{10}{|l|}{$\beta_{1}=1, \sigma_{1}=1$} \\
\hline $\operatorname{ADF}(T=100)$ & $\begin{array}{c}0.664 \\
(0.63)\end{array}$ & $\begin{array}{l}0.667 \\
(0.607)\end{array}$ & 0.07 & $\begin{array}{c}0.722 \\
(0.61)\end{array}$ & $\begin{array}{l}0.734 \\
(0.568)\end{array}$ & 0.106 & $\begin{array}{l}0.844 \\
(0.742)\end{array}$ & $\begin{array}{c}0.83 \\
(0.658)\end{array}$ & 0.122 \\
\hline$Z_{\alpha}$ & $\begin{array}{l}0.872 \\
(0.812)\end{array}$ & $\begin{array}{l}0.789 \\
(0.659)\end{array}$ & 0.115 & $\begin{array}{l}0.917 \\
(0.786)\end{array}$ & $\begin{array}{l}0.845 \\
(0.578)\end{array}$ & 0.169 & $\begin{array}{l}0.966 \\
(0.861)\end{array}$ & $\begin{array}{l}0.922 \\
(0.655)\end{array}$ & 0.206 \\
\hline$G H-A D F$ & $\begin{array}{l}0.881 \\
(0.846)\end{array}$ & $\begin{array}{l}0.639 \\
(0.50)\end{array}$ & 0.084 & $\begin{array}{l}0.818 \\
(0.758)\end{array}$ & $\begin{array}{l}0.62 \\
(0.465)\end{array}$ & 0.102 & $\begin{array}{l}0.862 \\
(0.793)\end{array}$ & $\begin{array}{l}0.669 \\
(0.441)\end{array}$ & 0.11 \\
\hline$G H-Z_{\alpha}$ & $\begin{array}{l}0.952 \\
(0.95)\end{array}$ & $\begin{array}{l}0.697 \\
(0.662)\end{array}$ & 0.058 & $\begin{array}{l}0.911 \\
(0.893)\end{array}$ & $\begin{array}{l}0.639 \\
(0.566)\end{array}$ & 0.067 & $\begin{array}{l}0.943 \\
(0.918)\end{array}$ & $\begin{array}{l}0.697 \\
(0.553)\end{array}$ & 0.077 \\
\hline$M L S$ & 0.373 & 0.277 & 0.794 & 0.338 & 0.232 & 0.744 & 0.224 & 0.184 & 0.732 \\
\hline$\widehat{\tau}_{1}, n=1$ & 0.536 & 0.515 & - & 0.495 & 0.465 & - & 0.393 & 0.383 & - \\
\hline$\widehat{\tau}_{1}, n=4$ & 0.812 & 0.839 & - & 0.830 & 0.810 & - & 0.722 & 0.732 & - \\
\hline$\widehat{\tau}_{2}$ & 0.000 & 0.000 & - & 0.000 & 0.000 & - & 0.000 & 0.000 & - \\
\hline $\operatorname{ADF}(T=200)$ & $\begin{array}{l}0.613 \\
(0.536)\end{array}$ & $\begin{array}{l}0.781 \\
(0.708)\end{array}$ & 0.083 & $\begin{array}{l}0.879 \\
(0.655)\end{array}$ & $\begin{array}{l}0.922 \\
(0.726)\end{array}$ & 0.165 & $\begin{array}{l}0.956 \\
(0.815)\end{array}$ & $\begin{array}{c}0.973 \\
(0.84)\end{array}$ & 0.201 \\
\hline$Z_{\alpha}$ & $\begin{array}{l}0.871 \\
(0.743)\end{array}$ & $\begin{array}{l}0.872 \\
(0.702)\end{array}$ & 0.167 & $\begin{array}{c}0.98 \\
(0.784)\end{array}$ & $\begin{array}{l}0.984 \\
(0.705)\end{array}$ & 0.35 & $\begin{array}{l}0.998 \\
(0.913)\end{array}$ & $\begin{array}{l}0.998 \\
(0.85)\end{array}$ & 0.429 \\
\hline$G H-A D F$ & $\begin{array}{l}0.743 \\
(0.677)\end{array}$ & $\begin{array}{l}0.761 \\
(0.687)\end{array}$ & 0.086 & $\begin{array}{l}0.814 \\
(0.648)\end{array}$ & $\begin{array}{l}0.838 \\
(0.628)\end{array}$ & 0.152 & $\begin{array}{l}0.919 \\
(0.775)\end{array}$ & $\begin{array}{l}0.921 \\
(0.726)\end{array}$ & 0.179 \\
\hline$G H-Z_{\alpha}$ & $\begin{array}{l}0.916 \\
(0.88)\end{array}$ & $\begin{array}{l}0.852 \\
(0.782)\end{array}$ & 0.097 & $\begin{array}{l}0.964 \\
(0.879)\end{array}$ & $\begin{array}{l}0.925 \\
(0.744)\end{array}$ & 0.16 & $\begin{array}{l}0.992 \\
(0.924)\end{array}$ & $\begin{array}{l}0.976 \\
(0.778)\end{array}$ & 0.201 \\
\hline$M L S$ & 0.67 & 0.332 & 0.894 & 0.427 & 0.192 & 0.812 & 0.259 & 0.118 & 0.803 \\
\hline$\widehat{\tau}_{1}, n=1$ & 0.584 & 0.538 & - & 0.400 & 0.381 & - & 0.304 & 0.292 & - \\
\hline$\widehat{\tau}_{1}, n=4$ & 0.894 & 0.871 & - & 0.768 & 0.743 & - & 0.614 & 0.604 & - \\
\hline$\widehat{\tau}_{2}$ & 0.000 & 0.000 & - & 0.000 & 0.000 & - & 0.000 & 0.000 & - \\
\hline
\end{tabular}


Figure 1: Stock Prices and Dividends (Sweden, UK and US)

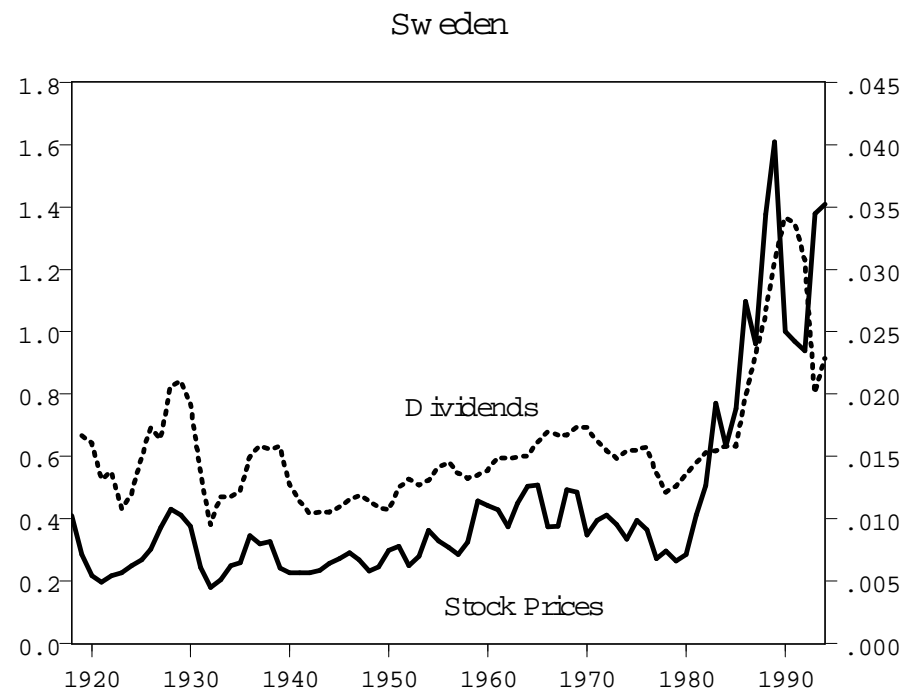

UK

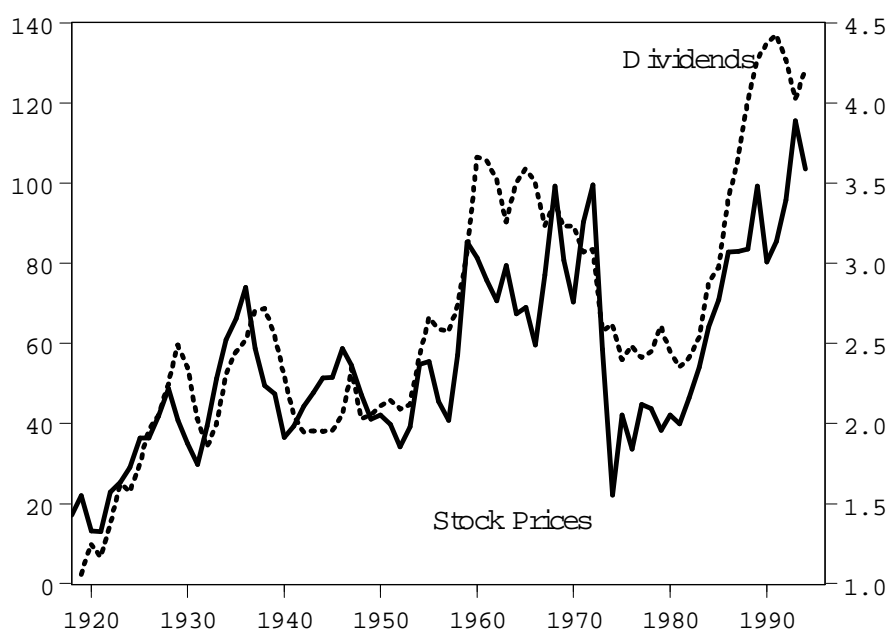

US

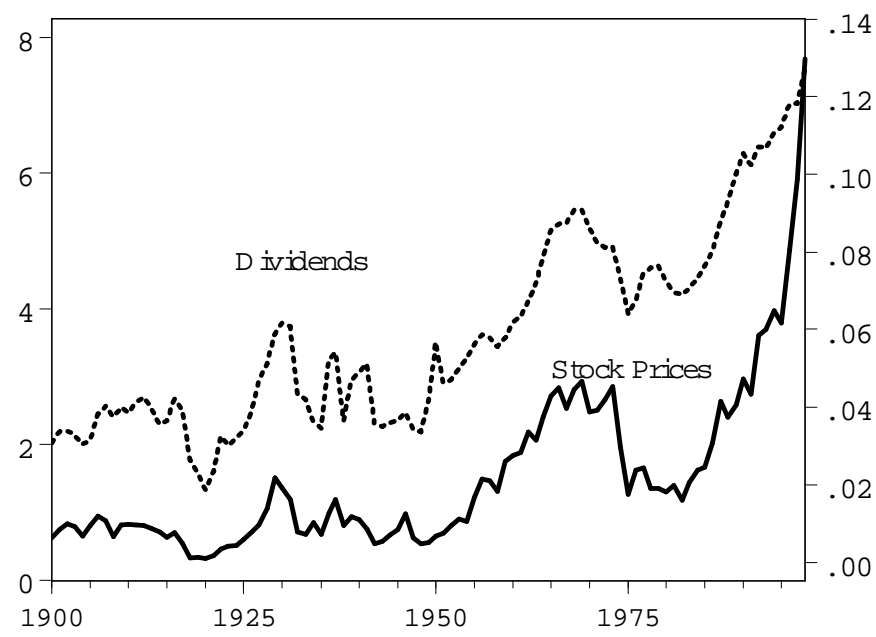


Figure 2: Estimates of $\beta_{t}$ - Sweden

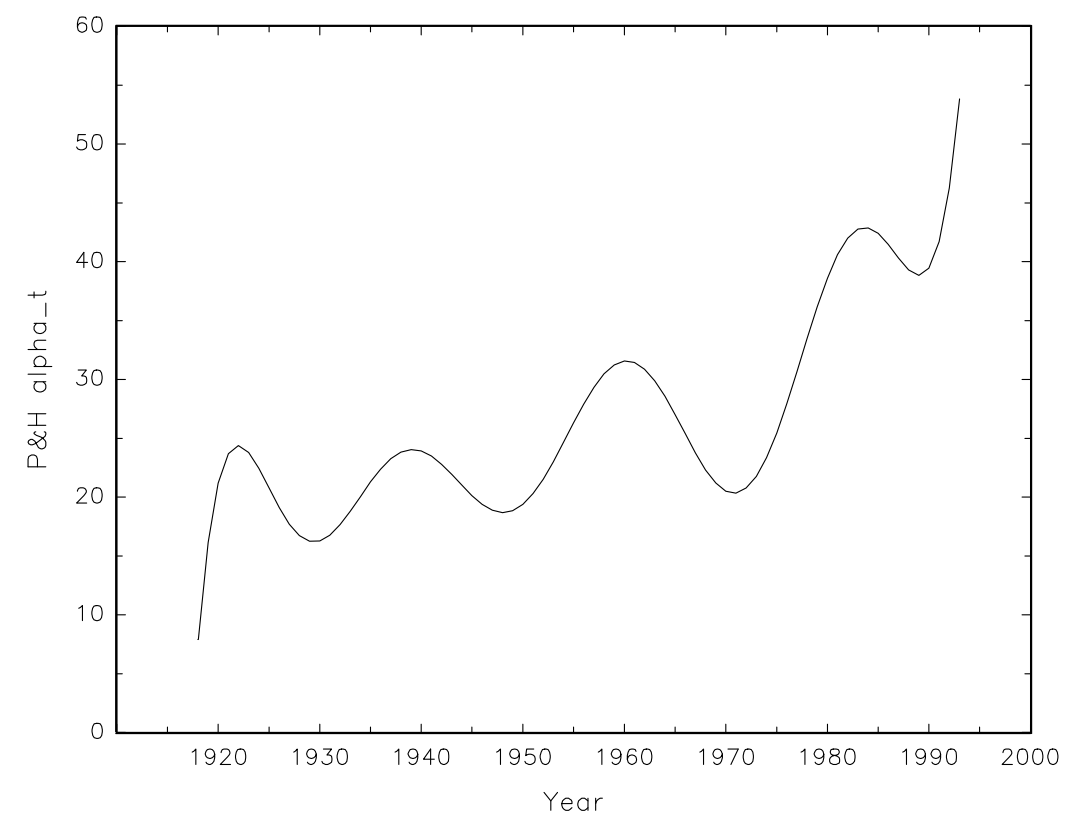

Figure 3: Estimates of $\beta_{t}$ - UK

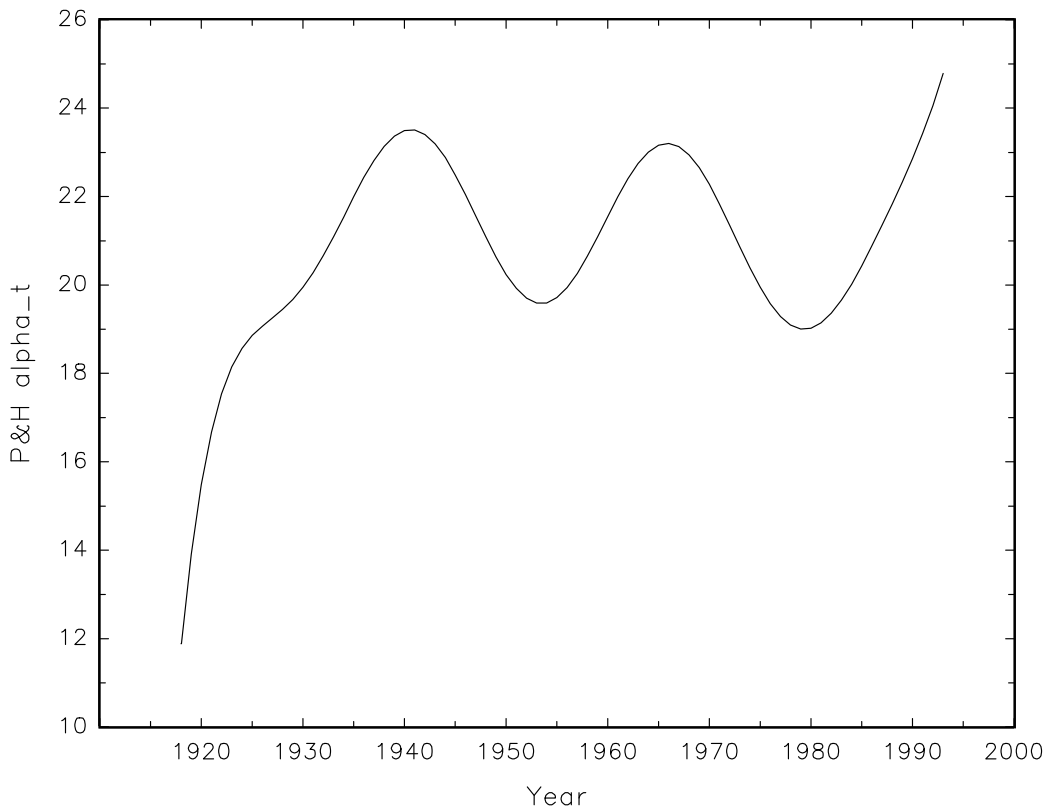


Figure 4: Estimates of $\beta_{t}$ - US

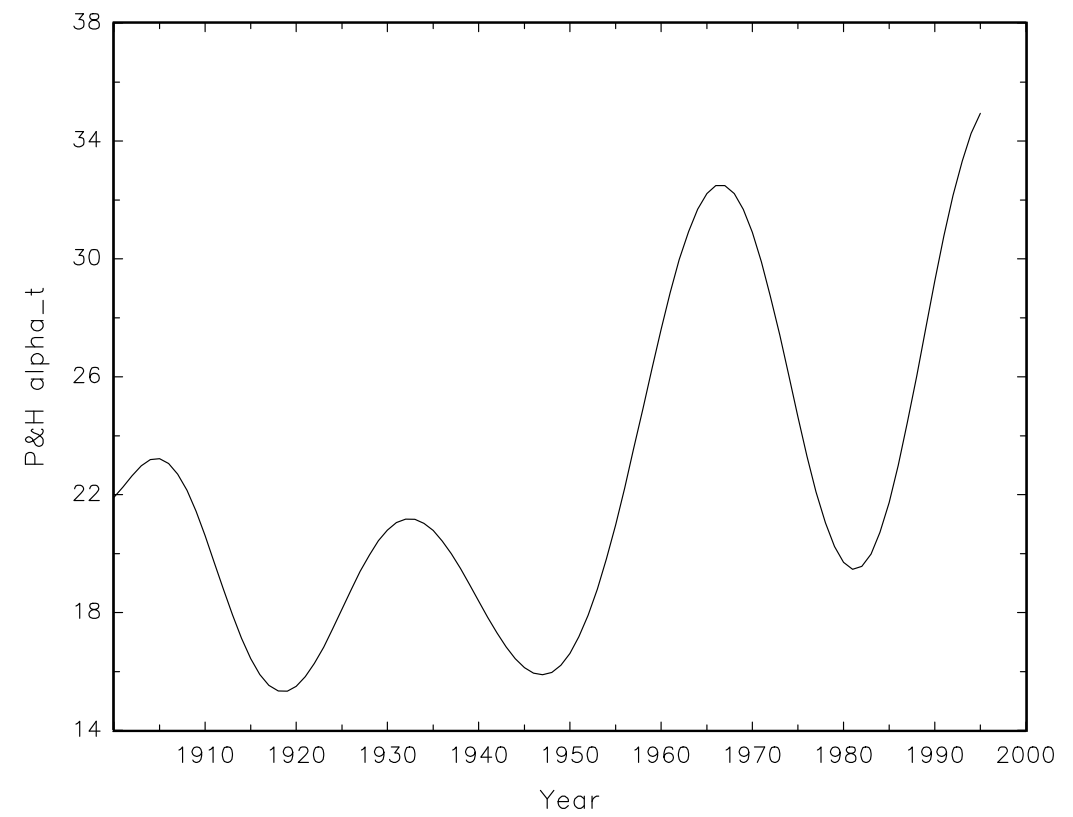

